\title{
Suppression of human lung cancer cell proliferation and metastasis in vitro by the transducer of ErbB-2.1 (TOB1)
}

\author{
Yang JIAO\#, Ke-kang SUN*, Lin ZHAO, Jia-ying XU, Li-li Wang, Sai-jun FAN*
}

Key Laboratory of Radiation Biology, School of Radiation Medicine and Protection, Medical College of Soochow University, Suzhou 215123, China

Aim: To investigate the effects of the transducer of ErbB-2.1 (TOB1) on the proliferation, migration and invasion of human lung cancer cells in vitro.

Methods: Human lung cancer cell lines (95-D, A549, NCl-H1299, NCl-H1975, NCl-H661, NCl-H446, NCl-H1395, and Calu-3) and the normal human bronchial epithelial (HBE) cell line were tested. The expression levels of TOB1 in the cells were determined with Western blot and RT-PCR analyses. TOB1-overexpressing cell line 95-D/TOB1 was constructed using lipofectamine-induced TOB1 recombinant plasmid transfection and selective G418 cell culture. The A549 cells were transcend-transfected with TOB1-siRNA. MTT assay, flow cytometry and Western blot analysis were used to examine the effects of TOB1 on cancer cell proliferation and wound healing. Transwell invasive assay was performed to evaluate the effects of TOB1 on cancer cell migration and invasion. The activity of MMP2 and MMP9 was measured using gelatin zymography assay.

Results: The expression levels of TOB1 in the 8 human lung cancer cell lines were significantly lower than that in HBE cells. TOB1 overexpression inhibited the proliferation of 95-D cells, whereas TOB1 knockdown with TOB1-siRNA promoted the growth of A549 cells. Decreased cell migration and invasion were detected in 95-D/TOB1 cells, and the suppression of TOB1 enhanced the metastasis in A549 cells. TOB1 overexpression not only increased the expression of the phosphatase and tensin homolog (PTEN), an important tumor suppressor, but also regulated the downstream effectors in the PI3K/PTEN signaling pathway, including Akt, ERK1/2, etc. In contrast, decreased expression of TOB1 oppositely regulated the expression of these factors. TOB1 also regulates the gelatinase activity of MMP2 and MMP9 in lung cancer cells.

Conclusion: The results demonstrate that the PI3K/PTEN pathway, which is essential for carcinogenesis, angiogenesis, and metastasis, may be one of the possible signaling pathways for regulation of proliferation and metastasis of human lung cancer cells by TOB1 in vitro.

Keywords: human lung cancer cells; transducer of ErbB-2.1 (TOB1); PTEN; carcinogenesis; metastasis; RNA interference

Acta Pharmacologica Sinica (2012) 33: 250-260; doi: 10.1038/aps.2011.163; published online 12 Dec 2011

\section{Introduction}

As one of the leading causes of cancer mortality in the world and the most common occupational cancer, lung cancer is becoming the biggest challenge for basic science ${ }^{[1]}$. Despite advances in surgery, radiotherapy, and chemotherapy, the mortality rate of lung cancer has not been substantially reduced over the past decades, largely because of potential metastasis. Metastasis is one of the most lethal attributes of

\footnotetext{
"These authors contributed equally to this work.

${ }^{*}$ To whom correspondence should be addressed.

E-mail sjfan@suda.edu.cn

Received 2011-08-18 Accepted 2011-11-03
}

cancer, responsible for about $90 \%$ of human cancer deaths ${ }^{[2]}$. Lung cancer metastasis involves a complex series of steps, including cellular migration, local invasion, dissemination, and angiogenesis. The inhibition of one of these processes can substantially prevent secondary tumors from spreading in the body ${ }^{[3,4]}$.

The tumor suppressor protein, which functions in cell cycle regulation, apoptosis induction, DNA damage repair, and metastasis inhibition, is a potential therapeutic target in lung cancer $^{[5-7]}$. One of the promising examples is $p 53$, whose mutation has been detected in $90 \%$ of small cell lung cancers and in $50 \%$ of non-small cell lung cancer. In 2006, Cristofanilli et $a l^{[8]}$ reported that adenovirus mediates p53 overexpression, 
which induces cell apoptosis in p53-null cells. These data documented a safety profile, encouraging clinical trials of adenovirus-mediated p53 in the therapy of lung cancer. However, evidence concerning other tumor suppressors thought to be responsible for lung cancer carcinogenesis, migration, and invasion still needs to be clarified.

The transducer of ErbB-2.1 (TOB1) gene was initially identified as a member of the anti-proliferative TOB/BTG (transducer of ErbB-2/B-cell translocation gene) protein family, which was first discovered in the $1990 \mathrm{~s}^{[9]}$. In mammalian cells, this family consists of BTG1, BTG2, BTG3, BTG4, TOB1, and TOB2. All the protein products of the family members possess the potential ability to restrain cell growth ${ }^{[10-13]}$. Carcinogenesis and tumor progression in lung, liver, and lymph nodes were observed in mice lacking TOB $1^{[14]}$. Furthermore, TOB1 deletion and dysfunction were also reported in human malignancies $^{[15,16]}$. These studies suggest that TOB1 acts as a tumor suppressor gene. Accumulating studies have also found that TOB1 might inhibit cell proliferation through its intervention in oncogenic pathways, including the epidermal growth factor and the TGF- $\beta /$ Smad signal pathways ${ }^{[17-19]}$. Although TOB1 expression is reduced in clinical lung cancer samples ${ }^{[15]}$, the effects of TOB1 on lung cancer proliferation and metastasis in vitro are poorly understood. The signaling pathways or the related mechanisms remain unclear.

In the present study, using Lipofectamine-mediated TOB1 recombinant plasmid and siRNA transfection of lung cancer cell lines, the effects of TOB1 on lung cancer proliferation, invasion, and migration are investigated in vitro. The possible pathways involved in its regulation of lung cancer tumorigenesis and metastasis are explored.

\section{Materials and methods}

\section{Cell culture}

The normal human bronchial epithelial (HBE) cell line and eight human lung cancer cell lines (95-D, A549, NCI-H1299, NCI-H1975, NCI-H661, NCI-H446, NCI-H1395, and Calu-3) were purchased from American Type Culture Collection (Manassas, VA, USA). Calu-3 cells were maintained in Dulbecco's modified Eagle's medium (DMEM). The other cells were seeded onto tissue culture dishes containing RPMI-1640 supplemented with $10 \%$ fetal calf serum (FCS), L-glutamine (5 mmol/L), non-essential amino acids (5 mmol/L), penicillin $(100 \mathrm{U} / \mathrm{mL})$, and streptomycin $(100 \mathrm{U} / \mathrm{mL})$ (Invitrogen, Carlsbad, CA, USA), at $37^{\circ} \mathrm{C}$ in a humidified $5 \% \mathrm{CO}_{2}$ atmosphere.

\section{Plasmids, siRNAs, and transfection}

The full-length human TOB1 cDNA was derived using polymerase chain reaction (PCR), using specific primers designed according to the TOB1 reference sequence from GenBank (NM_005749.2), and then cloned into the eukaryotic expression vector pcDNA3.0 (Invitrogen, Carlsbad, CA, USA). Three siRNA that target TOB1 mRNA and control (scrambledsequence) siRNA were designed and synthesized by Invitrogen. For stable transfection, the cells were transfected using Lipofectamine $2000^{\mathrm{TM}}$. After an additional 24-h incubation,
$500 \mu \mathrm{g} / \mathrm{mL}$ G418 (Sigma-Aldrich, MO, USA) was applied. After four weeks, the cell clones that overexpressed TOB1 were identified and obtained. Treatments with siRNA were performed as previously described ${ }^{[20]}$. Subconfluent lung cancer cells were transfected with each siRNA (40 nmol/L) using Lipofectamine $^{\mathrm{TM}}$ RNAiMAX reagent (Invitrogen, Carlsbad, CA, USA). Before the start of the following experiment, the cells were incubated for another $48 \mathrm{~h}$. The TOB1 inhibition efficiency by siRNA was determined using Western blot analysis. siRNA \#1 exhibited about 30\% decreased TOB1 expression, whereas no effect on TOB1 expression was observed in the control siRNA. Therefore, siRNA \#1 was selected for further studies. The sequences for TOB1-siRNA \#1 is as follows (5' to $3^{\prime}$ ): GCUGUAAGCCCUACCUUCATT UGAAGGUAGGGCUUACAGCTT

\section{Cell viability assay}

Cell proliferation was determined using a 3-[4,5-dimethylthiazol-2-yl]-2,5-diphenyl-tetrazolium bromide (MTT) viability assay, the most commonly used assay for determining cell growth and death. The MTT survival assay has been described in detail in previous studies ${ }^{[21]}$. Exponentially growing cells were recultured (5000 cells/well) overnight in 96-well tissue culture plates. Up to $20 \mu \mathrm{L}$ of MTT (Sigma-Aldrich, MO, USA) was directly added to the media in each well, with a final concentration of $2 \mathrm{mg} / \mathrm{mL}$. After 4-h incubation, the medium containing MTT was discarded, and $120 \mu \mathrm{L}$ of dimethyl sulfoxide was added for $10 \mathrm{~min}$. The absorbance was measured using an enzyme-linked immunosorbent assay reader at 570 $\mathrm{nm}$, with the absorbance at $630 \mathrm{~nm}$ as the background correction. The cell viability was expressed as the percentage of untreated controls. All experiments were performed at least three times.

\section{Cell cycle assays}

The cells were removed with trypsin and collected into centrifuge tubes together with the culture medium. All the contents were centrifuged for $5 \mathrm{~min}$ at $1800 \times g$. The supernate was poured out, washed once with $1 \times$ phosphate-buffered saline (PBS), and centrifuged for another $5 \mathrm{~min}$. The cells were finally fixed with $5 \mathrm{~mL}$ of pre-cooled $70 \%$ ethanol for at least $4 \mathrm{~h}$. The fixed cells were centrifuged and washed with $1 \times$ PBS. After centrifugation, the cell pellets were resuspended in 500 $\mu \mathrm{L}$ of propidium iodine $(10 \mu \mathrm{g} / \mathrm{mL})$ containing $300 \mu \mathrm{g} / \mathrm{mL}$ RNase (Sigma-Aldrich, USA). The cells were then incubated on ice for $30 \mathrm{~min}$, and then filtered with a 53- $\mu \mathrm{m}$ nylon mesh. The cell cycle distribution was calculated from 10000 cells using ModFit LT software (Becton Dickinson, CA, USA) using FACS Calibur (Becton Dickinson, San Jose, CA, USA).

\section{Transwell invasion assay}

The invasion assay was carried out using Transwell (Millipore, Billerica, MA, USA), as previously described ${ }^{[20]}$. The filter surfaces ( $8 \mu \mathrm{m}$ pore size) of the Transwell plates were uniformly coated with $25 \mathrm{mg}$ of Matrigel overnight at $4^{\circ} \mathrm{C}$ before the experiment. The lower chamber was filled with culture 
medium containing 10\% FCS. The subconfluent proliferating cells were carefully transferred onto the coated upper surface of the chamber. After 24-h incubation, the filter was gently removed, and the upper surface of the filter was wiped to remove all attached cells. The cells that invaded through the Matrigel and attached to the lower surface of the filter were fixed with $4 \%$ paraformaldehyde and stained with Giemsa. Three replicates were conducted for each condition, and 15 random fields in each replicate were chosen and counted using an Olympus CKX41 inverted microscope. The results are presented as the ratio of cells that invaded relative to the cells that invaded in the control conditions (cells seeded in serum-free media, and invaded towards 10\% FCS in DMEM). The results were obtained from at least three independent experiments.

\section{Wound healing assay}

In vitro cell migration was assessed using the scratch wound assay. The cells were subcultured onto six-well tissue culture plates to confluent cell monolayers using culture medium containing $10 \%$ FCS. The "wounds" were carefully created manually on the monolayers using sterile pipette tips, and the cellular debris was washed off with the desired medium. Phase contrast images of certain fixed positions in the wound area were taken at 0,24 , and $48 \mathrm{~h}$ after scratching using Olympus CKX41 microscope with a digital camera. In the images, the edge of the initial wound area was marked with lines using Image-Pro ${ }^{\circledast}$ Plus software (Media Cybernetics, Carlsbad, CA, USA). The edge of the initial wound area was overlaid with the image taken at 24 and $48 \mathrm{~h}$ after scratching. The number of cells migrating into the initial wound area was counted at 24 and $48 \mathrm{~h}$ after scratching. The data were obtained from three independent assays.

\section{Western blot and immunoprecipitation (IP)/immunoblot analyses}

Cell lysates were prepared and Western blot analysis was performed as previously described ${ }^{[22]}$. Equal aliquots of total cell protein (50 $\mu \mathrm{g}$ per lane) were electrophoresed on sodium dodecyl sulfate (SDS)-polyacrylamide gels, transferred onto polyvinylidene fluoride (PVDF) membranes, and then blotted using the following primary antibodies (Santa Cruz Biotech, Santa Cruz, CA, USA, 1:1000 dilution): $\beta$-actin (C-4), TOB (E-1), TOB1 (H-18), cyclin B1 (D-11), cyclin D1 (A-12), cyclin E (E-4), CDK2 (M2), PTEN (N-19), EGFR (1003), ERK1/2 (T-183), p-ERK1/2 (T185+Y187+T202+Y204), Akt (11E7), p-Akt (ser473), p-ІкВ-а (B9), NF-кB (P65A), MMP-2 (2C1), MMP-9 (6-6B), $\gamma$-catenin (G-20), $\alpha$-catenin (C-19), $\beta$-catenin (BD1080), E-cadherin (G-10); and secondary antibody horseradish peroxidase-labeled goat anti-mouse (GAM-007) and goat antirabbit (SC-2004) IgG. For the IP/Western blot, 1 mg lysate was immunoprecipitated with $1 \mu \mathrm{g}$ of anti-TOB (E-1) antibody at $4^{\circ} \mathrm{C}$ overnight. Protein A-Sepharose beads were added and incubated at $4^{\circ} \mathrm{C}$ for $2 \mathrm{~h}$, and the protein-bead complex was washed 5 times with radioimmunoprecipitation assay lysis buffer. The SDS-polyacrylamide gel electrophoresis (PAGE) was then performed to separate the immunoprecipitates.
The anti-TOB1 (H-18) and anti-PTEN (N-19) antibodies were applied for immunoblot. The protein bands were visualized using an enhanced chemiluminescence system (Union Bioscience Corporation, Hangzhou, China) with prestained markers as molecular size standards. The densitometry of the protein bands was quantified with Quantity One (Bio-Rad, Hercules, CA, USA), and the values were expressed relative to $\beta$-actin (control for loading and transfer). At least three independent experiments were performed for each cell type studied.

\section{Semiquantitative reverse transcription (RT)-PCR analysis}

mRNA expression was determined using semiquantitative RT-PCR assays. The PCR reaction conditions and cycle numbers were rigorously adjusted so that each reaction occurred within the linear range of amplification. The detailed methods for RNA isolation, cDNA synthesis, and RT-PCR analyses have been previously described ${ }^{[23]}$. For specific intent genes, the PCR primers were as follows: GAPDH sense, 5'-CAACTACATGGTCTACATGTTCC-3', anti-sense, 5'-CAACCTGGTCCTCAGTGTAG-3'; TOB1 sense, 5'-GGATCGACCCATTTGAGGTTTCT-3', anti-sense, 5'-CTACCCAAGCCAAGCCCATACAG-3'; PTEN sense, 5'-AGACCATAACCCACCACA-3', anti-sense, 5'-TTGACGGCT CCTCTACTG- 3 '. The PCR products were analyzed via electrophoresis through $1 \%$ agarose gels containing $0.1 \mathrm{mg} / \mathrm{mL}$ ethidium bromide (EB). The gels were photographed under ultraviolet light. The mRNA expression levels were quantified by densitometry of the cDNA bands using software Quantity One (Bio-Rad, Hercules, CA, USA). At least three independent experiments were performed for each cell type studied.

\section{Gelatin zymography assay}

The MMP-2 and MMP-9 activity of the supernates of lung cancer cells 95-D transfected or untransfected with TOB1 recombinant plasmid, as well as the RNAi-treated A549 cells, were identified using gelatin zymography assay as previously described ${ }^{[24]}$. At $24 \mathrm{~h}$ after transfection, all the cells were seeded onto 6-well plates at a final density of $3.0 \times 10^{5}$ cells/well. The supernatants were harvested after $24 \mathrm{~h}$ of additional incubation, and the conditioned media were collected by centrifugation at $13000 \mathrm{r} / \mathrm{min}$ for $5 \mathrm{~min}$ to remove the debris. The concentrations of the samples were quantified using bicinchoninic acid assay (Beyotime Institute of Biotechnology, Haimen, China). Then, $20 \mu \mathrm{g}$ of each protein sample was loaded under non-reducing conditions onto 10\% SDSpolyacrylamide gel containing $500 \mu \mathrm{g} / \mathrm{mL}$ gelatin (Amresco, Slon, OH, USA). After electrophoresis under $165 \mathrm{~V}$ for $1.5 \mathrm{~h}$, the gels were washed twice using washing buffer $(50 \mathrm{mmol} / \mathrm{L}$ Tris- $\mathrm{Cl} \mathrm{pH} \mathrm{7.6,} 10 \mathrm{mmol} / \mathrm{L} \mathrm{CaCl}_{2}$ ) with $2.5 \%$ Triton X-100 for $30 \mathrm{~min}$. Then, the gels were incubated overnight in zymography developing buffer containing $50 \mathrm{mmol} / \mathrm{L}$ Tris- $\mathrm{HCl}, \mathrm{pH}$ $7.5,10 \mathrm{mmol} / \mathrm{L} \mathrm{CaCl}_{2}, 150 \mathrm{mmol} / \mathrm{L} \mathrm{NaCl}$, and $0.02 \% \mathrm{NaN}_{3}$ at $37^{\circ} \mathrm{C}$. Then, $0.05 \%$ Coomassie Brilliant Blue R- 250 was utilized for gel staining, followed by destaining with a solution containing $30 \%$ methanol and $10 \%$ acetic acid. The gelatinase activity of the matrix metalloproteinases (MMPs) was then visualized as clear bands against the blue-stained background, 
and the density of the bands was analyzed using Quantity One software. At least three individual experiments were conducted with independent protein samples.

\section{Statistical analysis}

The data are presented as means and standard deviations (SD). Statistical comparisons of the experimental results between the treated group and the control group were made using two-tailed Student's t-test. All statistical tests were performed using SPSS version 17.0. $P$ value $\leq 0.05$ between groups was considered significant.

\section{Results}

TOB1 expression is decreased in eight lung cancer cell lines

TOB1 plays a role in suppressing the carcinogenesis of cancers, such as lung, thyroid, and breast cancers. However, the functional role of TOB1 in lung cancer has not yet been fully explored. To investigate the effect of TOB1 on proliferation and metastasis of lung cancer cells, the TOB1 expression levels in the eight lung cancer cell lines and in the normal bronchial epithelial cell line HBE were first analyzed using Western blot analyses and RT-PCR assays. As shown in Figure 1, the levels TOB1 protein and mRNA expression levels all decreased in the eight lung cancer cell lines, although at different levels. Compared with the immortalized normal epithelial cell line HBE, TOB1 mRNA expression decreased from $10 \%$ to $90 \%$ in almost all of the eight lung cancer cell lines $(P<0.05$, Figure $1 \mathrm{~A}$ and $1 \mathrm{C})$. Similar results were confirmed in TOB1 protein expression, as shown in Figure 1B and 1D, wherein the TOB1 protein levels decreased from $100 \%$ in the HBE cells to $20 \%$ to
$80 \%$. These in vitro data confirmed the findings of previous studies by Iwanaga et al ${ }^{[15]}$ that reducing TOB1 expression is an important event in lung cancer.

Ectopic expression of TOB1 regulates the proliferation of human lung cancer cells through alternation of the cell cycle

According to gain-of-function and loss-of-function approaches, the lung cancer cell lines 95-D and A549 were selected as model systems because 95-D cells express almost-deleted TOB1, whereas A549 cells express moderate TOB1. Using Lipofectamine and G418-mediated plasmid stable transfection, multiple clones stably transfected with TOB1 were selected and confirmed through RT-PCR and Western blot analysis in 95-D/TOB1 (Figure 2A). To investigate whether downregulated TOB1 expression enhances the aggressiveness of lung cancer cells, three different siRNA that target TOB1 and a control siRNA with a random sequence were generated and induced into A549 cells by transcend transfection. The efficacy of the siRNA was confirmed (Figure 2B). siRNA \#1 efficiently reduced TOB1 expression in both the mRNA and protein level; thus, it was selected for further studies.

MTT viability assays were conducted to elucidate the potential biological effects of TOB1 in lung cancer cells. As shown in Figure 2C, the 95-D/TOB1 transfectants displayed about 50\% reduction in proliferation rate compared with the "mock"transfected 95-D cells on d 4 and d 7. Conversely, the A549/ siRNA-TOB1-transfected cells showed a pronounced increase in growth rate at $\mathrm{d} 4$, and about $20 \%$ increase in proliferation on $\mathrm{d}$ 7. The results imply that TOB1 plays a key role in the growth control of lung cancer cells. Cell cycle analysis was
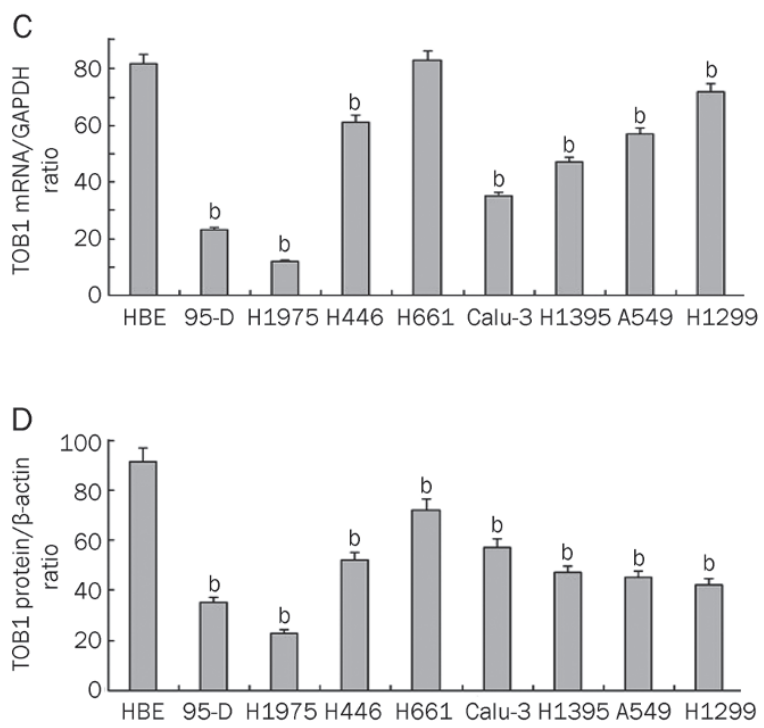

Figure 1. TOB1 expression is variably decreased in eight lung cancer cell lines. (A) Expression of TOB1 mRNA in lung cancer cell lines assayed via RTPCR; GAPDH was used as the loading control. Total RNA was extracted from normal and lung cancer cells. The 430 bp TOB1 cDNA fragments were separated and visualized by $1 \%$ agarose gel electrophoresis and ethidium bromide staining. (B) Expression of TOB1 protein in normal epithelial cell line $\mathrm{HBE}$ and eight lung cancer cell lines, separately assayed via Western blot analysis with $\beta$-actin as the loading control. Whole cell lysates (50 $\mu \mathrm{g})$ from each of the nine cell lines were separated using SDS-PAGE and transferred onto PVDF membranes. Bands were visualized using monoclonal anti-TOB1 antibodies with a chemiluminescence detection system. All experiments were performed independently at least three times. Mean \pm SD. ${ }^{b} P<0.05$ vs HBE cells. 
A

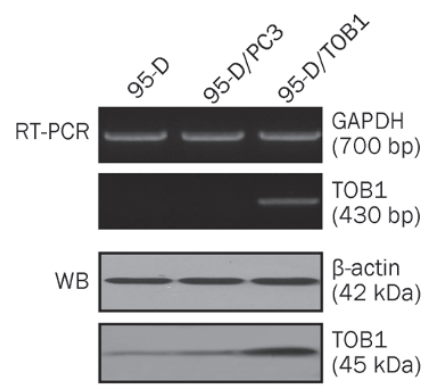

B

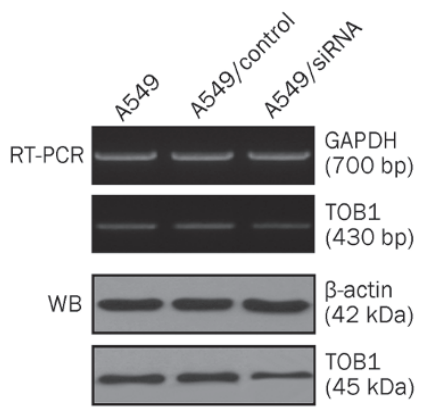

C
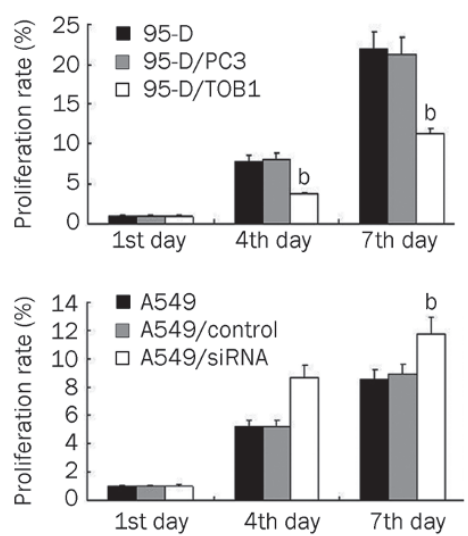

D
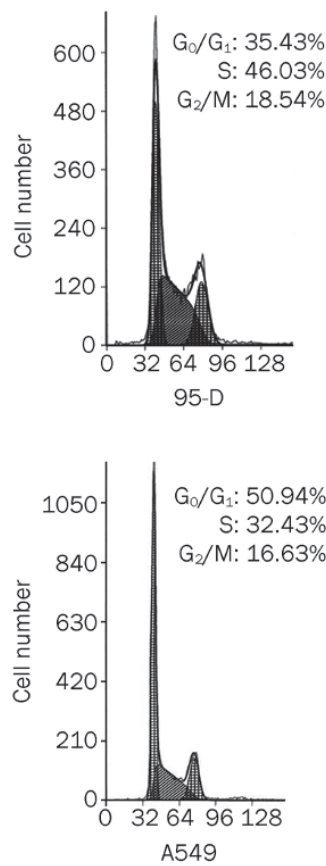
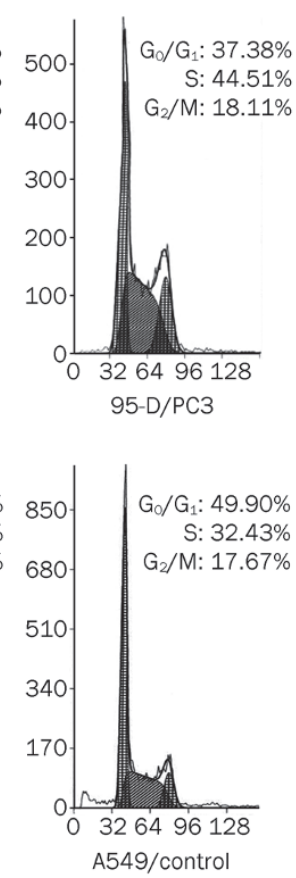

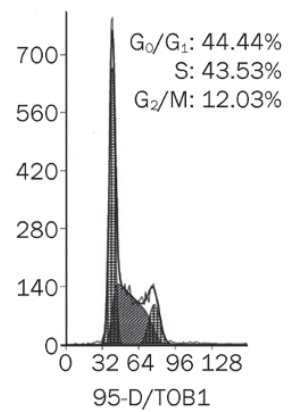

E

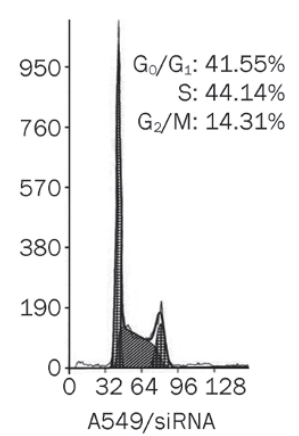

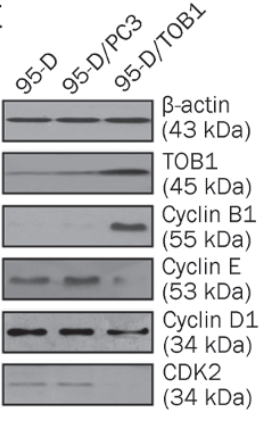

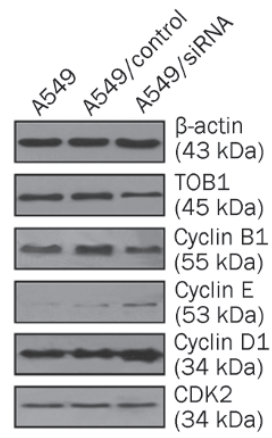

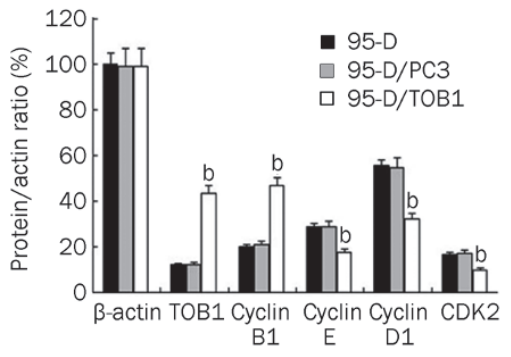

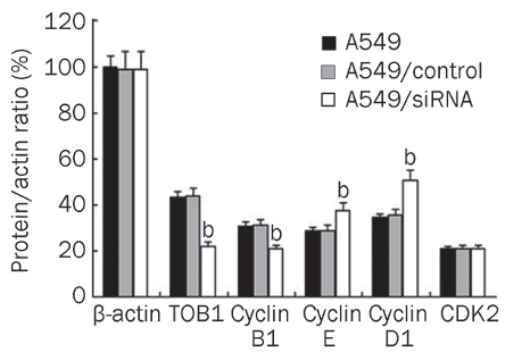

Figure 2. TOB1 regulates proliferation and modulates cell cycle progression of the non-small cell lung cancer cell lines 95-D and A549. (A) Ectopic TOB1 expression was confirmed via RT-PCR and immunoblotting in a 95-D/TOB1 transfectant and compared with vector-transfected parental cells. GAPDH and $\beta$-actin were used as the loading controls. (B) TOB1 expression was significantly reduced (at least 30\%) in A549/siRNA-TOB1 cells compared with the parental and control siRNA-transfected A549 cells. TOB1 expression was subjected to RT-PCR and Western blot using specific primer and monoclonal TOB1 antibody. GAPDH gene and $\beta$-actin protein expression were utilized as the loading controls. (C) TOB1 overexpression suppresses 95-D cell proliferation in MTT viability assays. In contrast, increased cell growth was observed in the A549/siRNA-TOB1 cells. A total of 4000 cells from each cell line were seeded in a 24-well plate. Cells were counted at d 1, 4, and 7. All samples were prepared in triplicate. The proliferation rate was measured as fold changes in cell growth. (D) TOB1 overexpression induced $G_{1}$ phase and $G_{2} / M$ phase arrest in the 95-D lung cancer cell line. The decreased TOB1 expression caused a decrease in the $\mathrm{G}_{1}$ population and an increase in the $\mathrm{S}$ phase population of $\mathrm{A} 549$ cells. Sub-confluent proliferating cells were stained with propidium iodide and subjected to FACS analysis to determine the cell cycle distribution. (E) In the 95-D cells, TOB1 overexpression increased cyclin B1 expression, and negatively regulated the expression of cyclin D1, cyclin E, and CDK2. TOB1-siRNA transfection increased the expression of cyclin D1 and cyclin E, but slightly reduced cyclin B1 expression. The cells were harvested using trypsin and centrifugation. Equal aliquots of the total protein $(50 \mu \mathrm{g})$ were analyzed by SDS-PAGE and blotted to detect cyclin B1, cyclin D1, and cyclin E protein expression. The protein expression was expressed as fold changes in band density, with $\beta$-actin as the loading control. All the experiments were performed independently at least three times. Mean \pm SD. ${ }^{b} P<0.05$ vs the control group.

then performed on the TOB1 transfectants and TOB1 knockdown lung cancer cells. The results in Figure 2D suggest that relative to the parental and vector-transfected "mock" cells, exogenous TOB1 overexpression in the 95-D cells significantly induced cell accumulation in the $\mathrm{G}_{1}$ phase $(t=7.16 ; P<0.05)$ and a modest decrease in percentage from $18 \%$ to $12 \%$ in the $G_{2} / M$ population $(t=6.83 ; P<0.05)$. Conversely, decreased TOB1 expression caused a decrease in the $\mathrm{G}_{1}$ population $(t=4.30$; 
$P<0.05)$ and an increase in the $S$ phase population $(t=7.01$; $P<0.05)$ compared with the parental or control siRNA-transfected A549 cells.

The functional role of TOB1 expression on cell cycle modulators was further investigated. The alterations in the different cyclins in TOB1-overexpressing or siRNA-TOB1 lung cancer cells were evaluated and compared with the parental or "mock" cells using Western blot analysis. Figure 2E shows that cyclin B1 expression increased three-fold in the 95-D/ TOB1 cells, but remarkably decreased in the siRNA-TOB1 A549 cells. The expression levels of cyclin E, CDK2, and cyclin D1 were significantly suppressed in the 95-D/TOB1 cells. In contrast, cyclin E and cyclin D1 expression were both increased in the A549/siRNA-TOB1-transfected cells. These results suggest that TOB1 might partly participate in cell cycle progression regulation by adjusting cyclin expression.

\section{Alteration of the aggressiveness of lung cancer cells by TOB1 protein}

A critical event in tumor metastasis and progression is the ability of tumor cells to invade the extracellular matrix, allowing tumor cells to move beyond the restrictions of the primary tumor environment. To examine the competence of cells to invade through biological matrices in vitro, Transwell assay was carried out as described previously ${ }^{[20]}$. The results show that compared with the parental cells, amplified TOB1 expression vigorously inhibited the ability of the 95-D cells to invade through the filter coated with Matrigel. As shown in Figure $3 \mathrm{~A}$, the invasion rate of 95-D/TOB1 cells decreased by more than $80 \%$ corresponding to the parental and vector-transfected cells $(t=68.56 ; P<0.05)$. In contrast, the invasion rate of A549 cells transfected with TOB1-siRNA increased by 2.5 -fold $(t=5.17 ; P<0.05)$ in contrast to the control cells (Figure 3B).

To determine whether the decreased invasiveness caused by TOB1 is associated with cell motility, the effect of TOB1 on cell migration capacity was analyzed using a wound healing assay $^{[25]}$. The cells were scratch-wounded with sterile pipette tips and post-incubated for an additional $48 \mathrm{~h}$. Figure 3C and 3D show that cell flattening and spreading along the edges of the wound were significantly more obvious in the A549/ siRNA cells than in the A549 cells $(t=6.51 ; P<0.05)$, and were significantly lesser in 95-D/TOB1 cells than in the parental lung cancer cells $(t=5.93 ; P<0.05)$.

Taken together, these results indicate that TOB1 gene expression significantly inhibits cell invasion and migration in vitro, and the knockdown of TOB1 conversely increases the ability of lung cancer cells to invade and migrate.

TOB1 mediates anti-metastasis effects through alterations of PTEN-mediated modulation of downstream signaling

RT-PCR and Western blot analysis were utilized to identify additional targets of TOB1 that might be involved in downregulating lung cancer metastasis. PTEN, an important tumor suppressor mutated in a wide range of malignancies second only to p53, which is a central negative regulatory factor of epidermal growth factor receptor (EGFR) downstream of phosphoinositide 3 kinase (PI3K)-Akt (Akt8 virus oncogene cellular homolog) pathway. It plays a key role in cell proliferation, survival, and malignant transformation by regulating the mitogen-activated protein kinase (MAPK) and the PI3K/Akt and integrin-focal adhesion kinase (FAK) pathways. Recent studies have investigated several signaling pathways, such as MAPK and Akt, through which TOB1 conducts its tumor suppressor activity. In lung cancer, the functional pathways of TOB1 remain to be elucidated.

In the present study, RT-PCR was used to detect the effects of TOB1 on PTEN mRNA expression. TOB1 overexpression in the 95-D cells increased PTEN mRNA expression up to twofold in the control cells, whereas PTEN mRNA was reduced in the TOB1-siRNA-transfected A549 cells (Figure 4A). Western blot analysis was then conducted to identify the effects of TOB1 on the PI3K/PTEN pathways. The results show that TOB1 overexpression slightly decreased EGFR expression, thereby significantly suppressing the expression of downstream effecters Akt and ERK1/2, but had no obvious effects on the expression of these proteins. Reduced NF-KB (p65) and increased IKB- $\alpha$ phosphorylation were observed in the 95-D/TOB1 cells. TOB1 overexpression amplified E-cadherin expression and slightly downregulated $\alpha-/ \beta-/ \gamma$-catenin (Figure $4 \mathrm{~B})$. In addition, decreased MMP-2 and MMP-9 expression were also detected in the 95-D/TOB1 cells. In the TOB1knockdown A549 cells, the contradictory effects on almost all these downstream factors were confirmed, as shown in Figure $4 \mathrm{C}$. The variations in gene expression caused by the different TOB1 expression levels suggest that TOB1 might be a multifunctional regulator of the metastasis of lung cancer cells. The effects of TOB1 expression on the activities of MMPs were also determined with a gelatin zymography assay, as shown in Figure 4D. TOB1-overexpressing 95-D cells exhibited decreased MMP2 $(t=4.61 ; P<0.05)$ and MMP9 $(t=6.19 ; P<0.05)$ activity in contrast to the parental and mock-transfected cells. RNAiinduced TOB1 knockdown in the A549 cells increased MMP2 activity to some extent $(t=9.10 ; P<0.05)$.

These results reveal the ability of TOB1 to regulate most of the important downstream factors of the PI3K/PTEN signal pathway; therefore, the potential interaction between PTEN and TOB1 was further examined through an IP/immunoblot assay. The results indicate that the presence of PTEN protein in the TOB1 IP of the A549 cells containing the wild-type PTEN gene and moderate TOB1 gene expression, as shown in Figure 4E. In the TOB1-suppressed A549 cells, this proteinprotein association was still observed, but to a lesser extent. Neither PTEN nor TOB1 was found in the normal mouse IgG IP, which was the negative control for the IP assay (data not shown). The results imply that TOB1 is actually associated with PTEN in the A549 cells.

\section{Discussion}

Recently, accumulated evidence has indicated that the TOB1 gene is involved in the negative regulation of cell growth and functions as a tumor suppressor ${ }^{[26-28]}$. Alterations in TOB1 expression have been reported in a variety of human malig- 

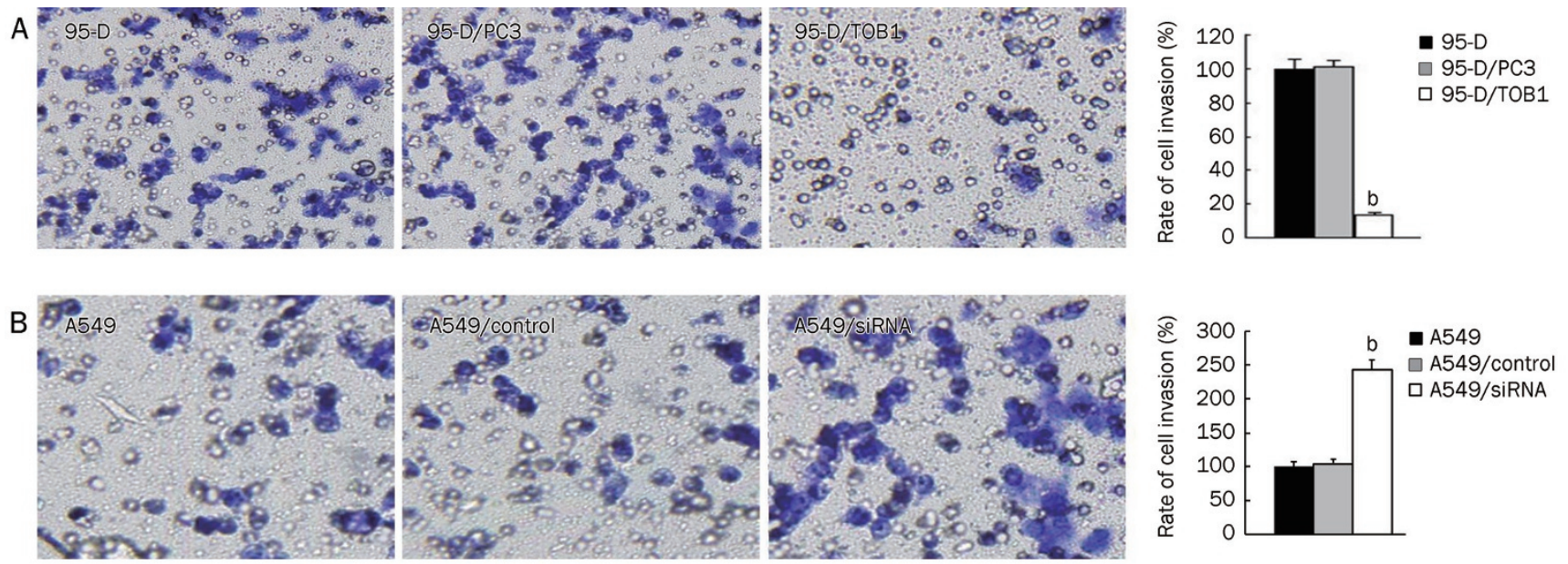

C
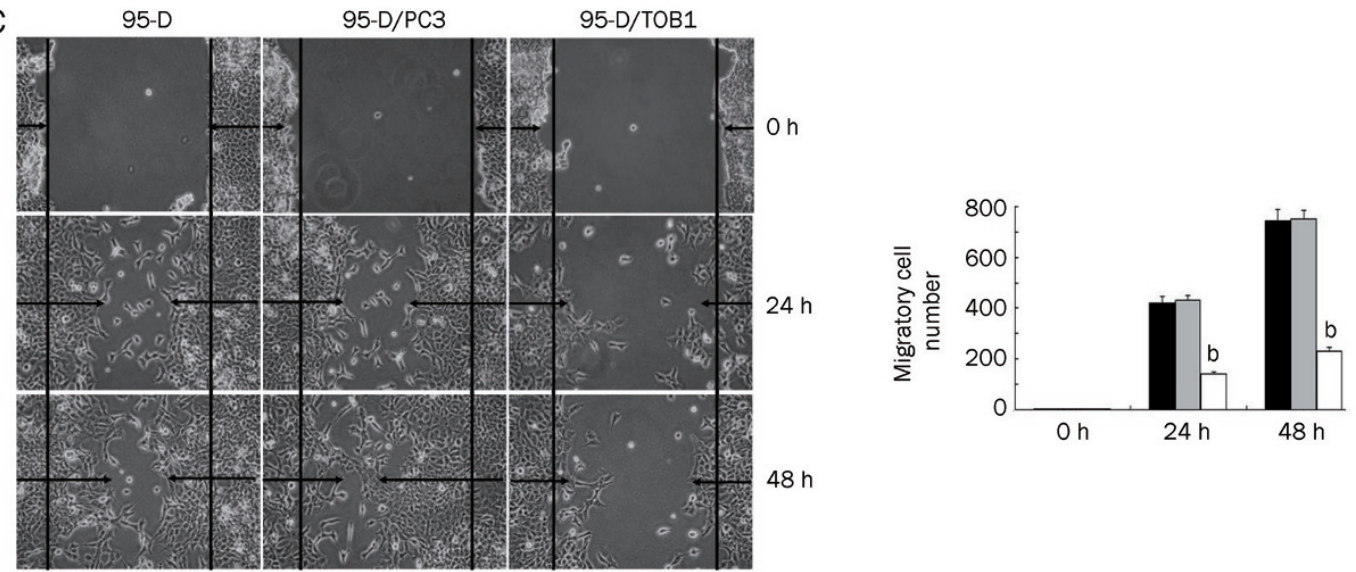

- 95-D

95-D/PC3

口 95-D/TOB1

$48 h$
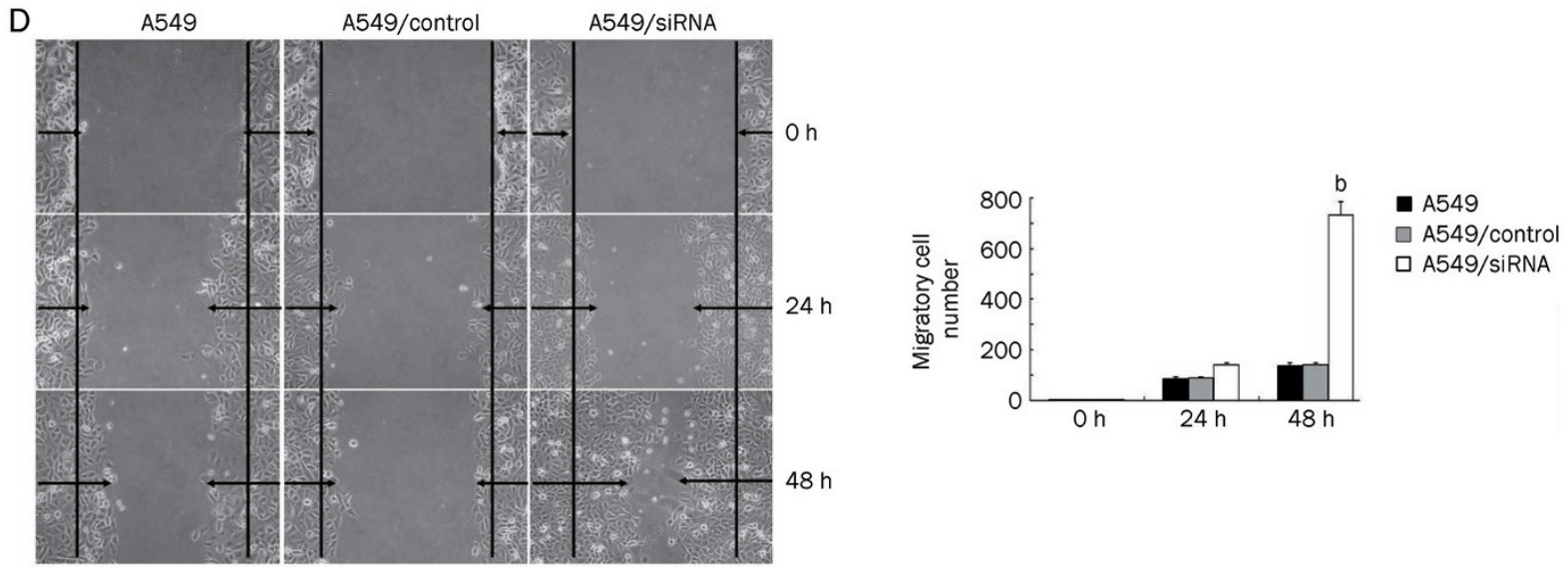

Figure 3. TOB1 expression is inversely correlated with lung cancer cell metastasis in vitro. (A) TOB1 overexpression prevented highly invasive 95-D cells from invading. 95-D, 95-D/PC3, and 95-D/TOB1 cells grown to subconfluence were trypsinized and transferred into the upper compartment of the modified Transwell chambers $\left(3 \times 10^{5}\right.$ cells/chamber). RPMI 1640 plus $10 \%$ FCS (500 $\mu \mathrm{L} /$ chamber) as a chemo attracter was added to the lower compartment. After $24 \mathrm{~h}$ incubation, the invasive cells attached to the lower surface of the Matrigel-coated filter were fixed, stained, and photographed under a phase contrast microscope and then counted in 15 randomly selected microscopic fields. ${ }^{\mathrm{b}} P<0.05 \mathrm{vs}$ the control group. (B) Less invasive A549 cells regained their invasiveness with the knockdown of TOB1 expression. Exponential A549, A549/control siRNA, and A549/siRNA-TOB1 cells were seeded onto the modified Transwell chambers $\left(3 \times 10^{5}\right.$ cells/chamber). After $24 \mathrm{~h}$ of chemoattraction with $10 \%$ FCS, the cells that invaded through the artificial basement membrane were visualized, counted, and analyzed. ${ }^{b} P<0.05$ vs the control group. (C) Ectopic TOB1 expression decreased lung cancer cell migration ability. Confluent 95-D, 95-D/PC3, and 95-D/TOB1 cells cultured in six-well dishes were carefully wounded using sterile pipette tips. After 12 or $24 \mathrm{~h}$, the cells were photographed under a phase contrast microscope. (D) Confluent A549, A549/control siRNA, and A549/siRNATOB1 cells were also wounded as described above. The number of cells migrating into the initial wound area was counted and expressed as mean \pm SD. ${ }^{\mathrm{b}} \mathrm{P}<0.05$ vs the control group. All experiments were performed at least three times independently. 

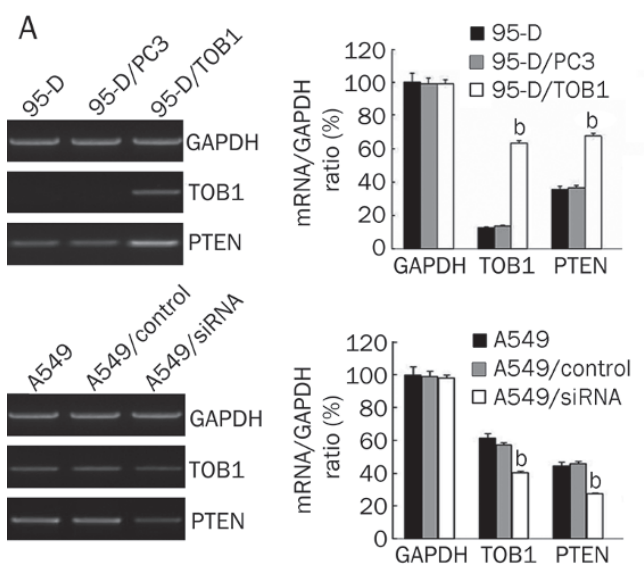
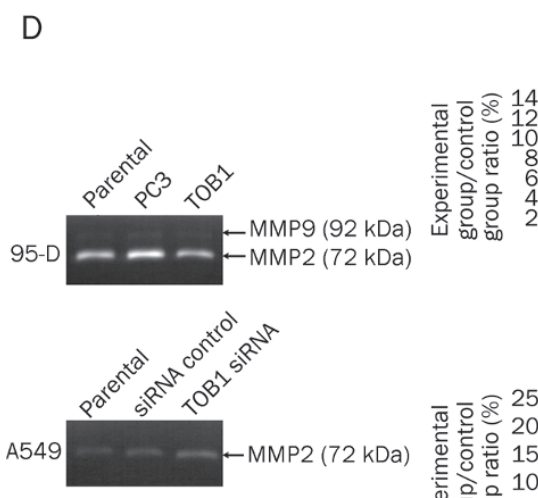

$\mathrm{E}$

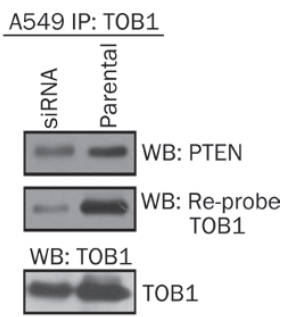

B
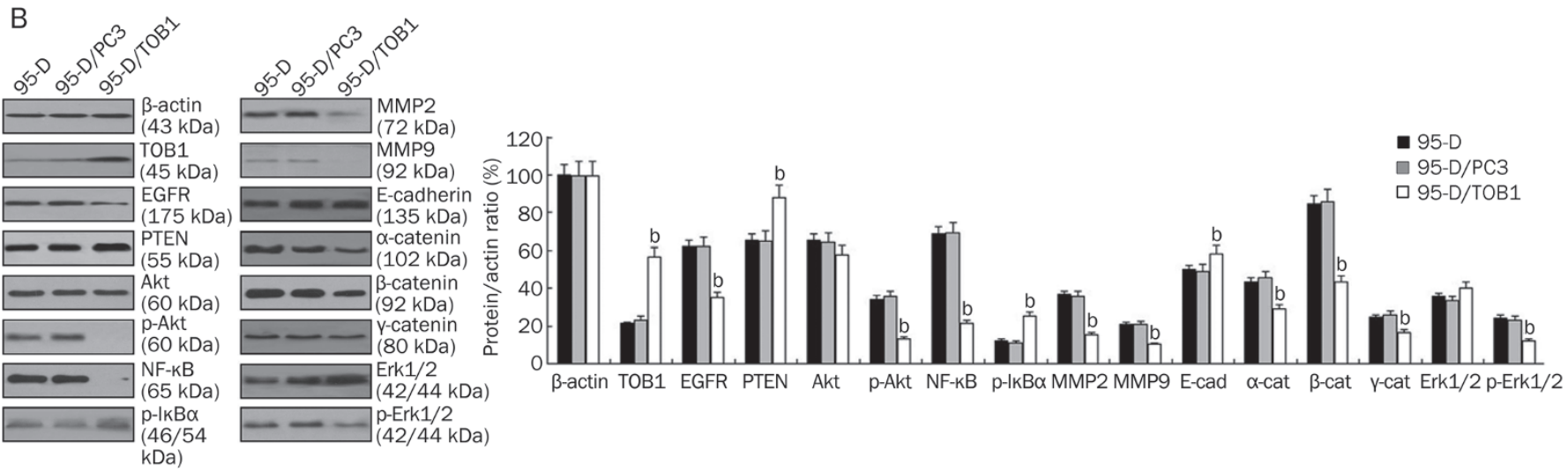

C
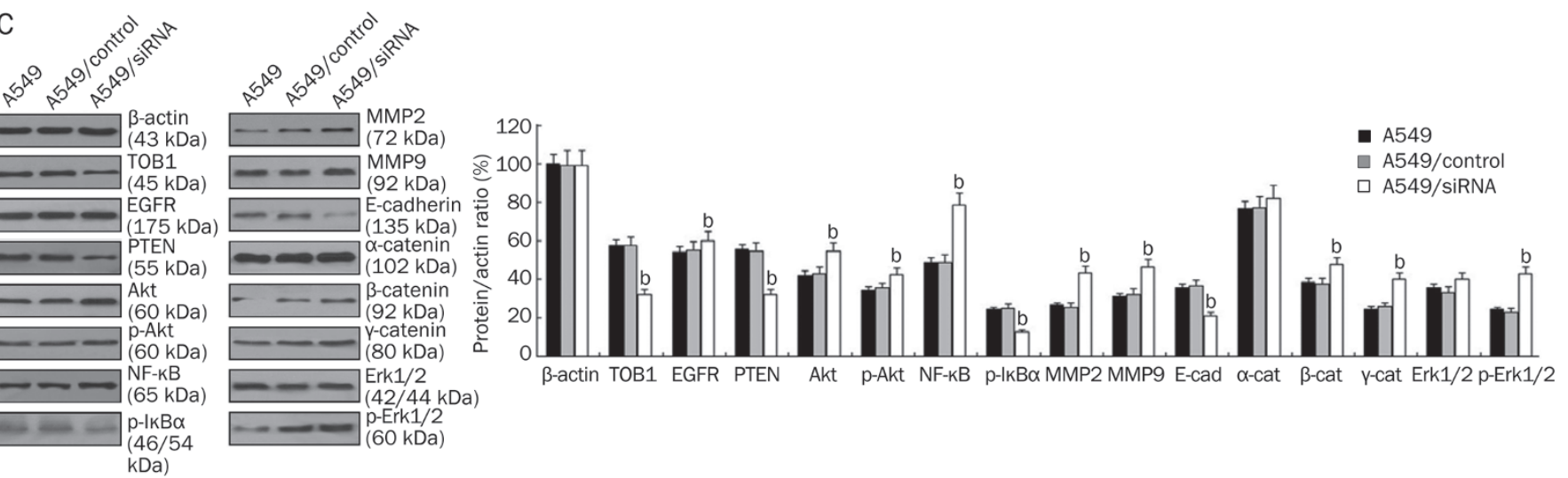

Figure 4. TOB1 is involved in the modulation of PI3K/PTEN downstream signaling pathways. (A) TOB1 regulated PTEN expression. RT-PCR assays were performed to determine the expression of PTEN mRNA in TOB1-overexpressing 95-D cells and TOB1 knockdown A549 cells. The PCR products were separated and visualized via agarose gel electrophoresis. mRNA expression was measured as fold changes in band density, with GAPDH as the loading control. ${ }^{\mathrm{b}} \mathrm{P}<0.05$ vs the control group. (B) Whole cell lysates from 95-D/TOB1, 95-D parental cells, and vector "mock"-transfected 95-D cells were prepared, and $50 \mu \mathrm{g}$ of proteins were resolved using SDS-PAGE, followed by immunoblotting with the indicated specific antibodies against EGFR, PTEN, TOB1, p-AKT, AKT, p-ERK1/2, ERK1/2, NF-KB, p-IKB- $\alpha$, E-cadherin, $\alpha$-catenin, $\beta$-catenin, and $y$-catenin. (C) A549, A549/control siRNA, and A549/siRNATOB1 cells were harvested, and equal aliquots of the protein were subjected to a Western blot assy. The expression and activity of specific downstream factors in the PI3K/PTEN pathway were detected. The expression levels are displayed as fold changes in band density. ${ }^{b} P<0.05$ vs the control group. (D) TOB1 affected activities of MMP2 and MMP9 in A549 and 95-D cells. The conditioned medium was collected and quantified, and $20 \mu g$ total protein per sample was separated by SDS-PAGE containing $500 \mu \mathrm{g} / \mathrm{mL}$ gelatin. After incubation, developing, and staining, the gelatinase activity of the MMPs was visualized and analyzed as band density. ${ }^{b} P<0.05$ vs the control group. The representative zymograph was from three independent experiments. (E) TOB1 forms protein-protein complex with PTEN. Whole cell lysates were prepared from A549 and A549/siRNA-TOB1 cells. About 1 Hg of lysate was immunoprecipitated with anti-TOB antibodies. The immunoprecipitated proteins were subsequently separated by SDS-PAGE, followed by immunoblotting with anti-PTEN antibody, and then reprobing with TOB1 antibodies. 
nancies including thyroid and breast cancers ${ }^{[26]}$. In human lung cancer, in 2003, Iwanaga et al ${ }^{[15]}$ reported reduced TOB1 expression in most of his 43 clinical specimens, but the exact biological effects of TOB1 on lung cancer carcinogenesis and progression remain unclear. In the present study, based on gain-of-function and loss-of-function principles, the roles of TOB1 in lung cancer cells have been demonstrated and TOB1mediated downstream signaling pathways have been preliminarily explored. First, the variously decreased TOB1 mRNA and protein expression was revealed in eight lung cancer cell lines in contrast to the normal HBE cell line. These in vitro data confirm the findings of Iwanaga et $a l^{[15]}$ that suppressed TOB1, which may be a tumor suppressor, is an important factor in human lung cancer cells.

One of the essential functions of tumor suppressors is to suppress tumor growth effectively by negatively regulating the cell cycle and/or inducing apoptosis ${ }^{[29-31]}$. The antiproliferation activity of TOB1 in 95-D cells in vitro is because of increased TOB1 expression. Conversely, siRNA-mediated TOB1 downregulation in the A549 cells led to promoted growth rate, providing a supplementary confirmation for the gain-of-function experiments. The cell cycle analysis also provided evidence that TOB1 induces cell cycle arrest in lung cancer cells. Ectopic TOB1 expression in the 95-D cells caused an accumulation of cells in the $G_{1}$ and $G_{2} / M$ phases and decreased the percentage of cells entering the $S$ phase. TOB1 knockdown led to the S phase arrest of A549 cells. TOB1 overexpression results in increased cyclin B1 and decreased expression of cyclin D1, cyclin E, and CDK2. Together with the loss-of-function experiments, these results provide further evidence that the antitumor effects of TOB1 in the lung cancer cells are partly caused by its regulation of the cell cycle.

Despite cell cycle regulation and apoptosis induction, several tumor suppressors are involved in preventing tumor cells from dispersing, blocking loss of contact inhibition, and inhibiting metastasis ${ }^{[32-35]}$. We demonstrated for the first time that TOB1 overexpression significantly inhibits the ability of the highly invasive lung cancer cell line 95-D to invade through an artificial basement membrane and prevents cell migration in vitro. For the less invasive A549 cells, the partial knockdown of TOB1 by siRNA significantly promotes their invasiveness and migration in vitro.

In lung cancer, one of the well-studied pathways is EGFR and its downstream signaling cascade, which is involved in cellular proliferation, apoptosis, and metastasis ${ }^{[36]}$. The EGFR pathway has already been clinically accepted as a therapeutic target in advanced non-small cell lung cancer and other solid tumors in recent years ${ }^{[37]}$. Principle data suggest that EGFR heterodimer or homodimer formation induced by ligand binding activates the intracellular tyrosine kinase domain, consequently inducing additional downstream pathways via PLC$\gamma, \mathrm{MAPK}$, and PI3K, and finally affecting cell survival and metastasis through these downstream cascades ${ }^{[38-40]}$. In the current study, TOB1 overexpression reduced EGFR expression, whose phosphorylation is involved in MAP kinase signaling activation ${ }^{[41,42]}$. Significantly decreased MAPK
(ERK1/2 T185+Y187+T202+Y204) and Akt (Ser473) activity was observed in TOB1-transfected 95-D cells. Conversely, increased EGFR, MAPK, and Akt activity was observed in TOB1-knockdown A549 cells. Drastically reduced NF-KB (p65) and increased phosphorylation of ІкB- $\alpha$ were observed in TOB1-overexpressing 95-D cells. In contrast, TOB1-siRNA promoted NF-кB expression and suppressed ІкB- $\alpha$ phosphorylation. These results are correlated with the findings of Kojima et $a l^{[43]}$ that the activation NF-kB stimulates invasion and metastasis via its regulation of MMP and cyclin D1 expression. We also found that variations in cellular TOB1 protein profoundly affect the expression of E-cadherin, $\alpha-, \beta-$, and $\gamma$-catenin. Meanwhile, $\alpha-, \beta-$, and $\gamma$-catenin bind to the highly conserved intracellular cytoplasmic tail of E-cadherin, and the catenin/cadherin complexes play important roles in mediating cellular adhesion ${ }^{[4-46]}$. Aside from its biological function, when not complexed with cadherins, $\beta$-catenin is an important downstream factor in the Wnt/ $\beta$-catenin pathway ${ }^{[47,48]}$, which can interact with transcription factors and regulate gene transcription; thus, it is involved in the regulation of proliferation and differentiation. The negative regulation of the expression of $\beta$-catenin and the downstream factors of $\mathrm{Wnt} / \beta$-catenin pathway by TOB1 inhibited $\beta$-catenin transcriptional activity ${ }^{[49]}$. In the 95-D/TOB1 and A549-siRNA TOB1 cells, varied MMP-2 and MMP-9 expression and activity is responsible for the degradation of extracellular matrix components, including collagen, gelatin, fibronectin, laminin, and proteoglycans ${ }^{[50-52]}$. Thus, suppression of $\beta$-catenin-regulated transcription, which induces the expression of proliferative and progressive genes such as cyclin D1 and MMPs via the PI3K/PTEN pathway, may at least mediate the anti-proliferative and anti-metastasis function of TOB1 in lung cancer cells ${ }^{[53,54]}$.

In addition, the solid protein-protein interaction between TOB1 and PTEN in human lung cancer A549 cells, aside from the expression regulation effects of TOB1 on PTEN, is shown for the first time. These results provide several clues to outline the signal cascades and specific targets of TOB1-related proliferation and metastasis regulation in lung cancer cells (Figure $5)$.

In conclusion, TOB1 is expressed in normal HBE cells, and the reduction of TOB1 expression is a common event in eight lung cancer cell lines. TOB1 functions as a tumor suppressor in NSCLC 95-D and A549 cells by modulating EGFR and its downstream signaling pathways through the direct or indirect interaction with the key tumor suppressor PTEN ${ }^{[55,56]}$. However, whether the biological effects of TOB1 in lung cancer cells are triggered by its regulation on PTEN expression as a transcription factor or by its effect on PTEN phosphatase activity remain unclear. Whether TOB1 affects PTEN through other mechanisms, such as PTEN phosphorylation, ubiquitination, acetylation, or oxidation, in terms of carcinogenesis and progression is unknown. Further studies on the involvement of TOB1 in lung cancer carcinogenesis and progression are necessary; these will allow the development of more accurate theories to guide therapeutic practice. 


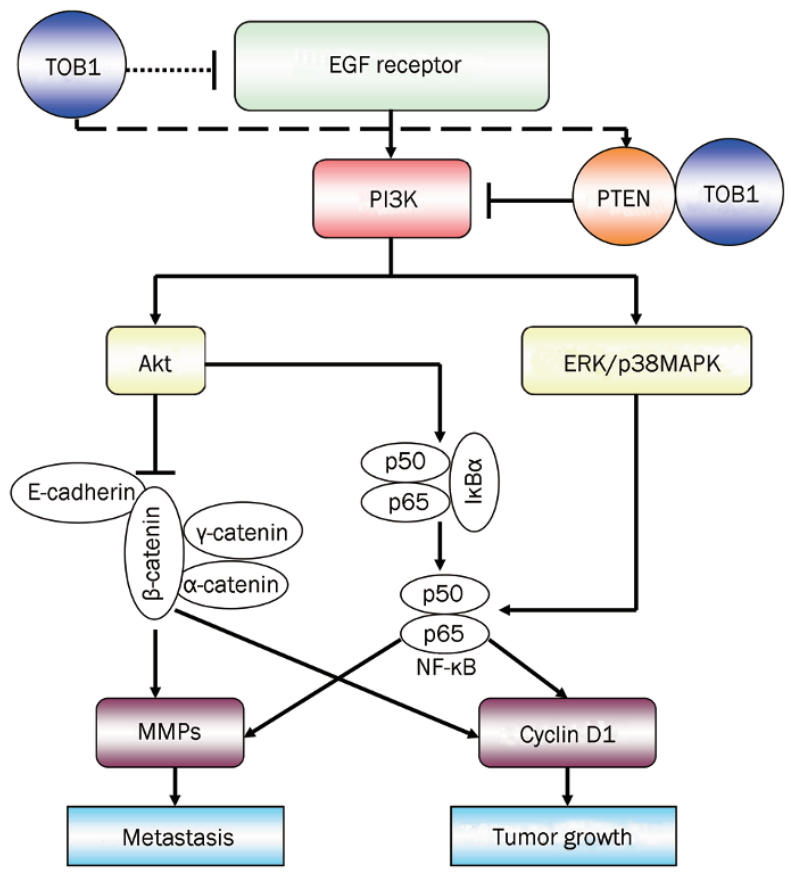

Figure 5. TOB1 was involved in regulation of tumor growth and metastasis via the PI3K/PTEN signaling pathway. The binding of EGF to the corresponding EGF receptors activates PI3K and downstream signaling pathways, including Akt and ERK/p38 MAPK, leading to the activation of NF-KB gene expression. Consequently, the expression of cyclin D1 and MMPs are increased, resulting in the promotion of lung cancer tumorigenesis and metastasis. Despite its activation of NF-kB, Akt can also inhibit $\beta$-catenin expression, which plays an important role in mediating cellular adhesion together with $\alpha$ - and $\gamma$-catenin/cadherin complexes. In the present study, TOB1 was identified as a negative regulator of EGFR expression, increasing the expression of PTEN, which functions as the central negative regulator of the PI3K/AKT pathway in controlling tumorigenesis and metastasis. The protein-protein interaction between TOB1 and PTEN was detected for the first time in cultured lung cancer cells; hence, TOB1 may be a regulator of PTEN activity.

\section{Acknowledgements}

This work was supported by grants from the Program for Changjiang Scholars and Innovative Research Team in University (IRT0849), the National Natural Science Foundation of China (No 81071906), the Doctoral Fund of Ministry of Education of China (K512602110), the College Nature Science Foundation of Jiangsu Province (SZ126821), and the Priority Academic Program Development of Jiangsu Higher Education Institutions.

\section{Author contribution}

Ke-kang SUN, Lin ZHAO, Jia-ying XU, and Li-li WANG performed experiments and interpreted data; Yang JIAO and Saijun FAN supervised all aspects of this research; and Ke-kang SUN and Yang JIAO prepared the manuscript.

\section{References}

1 Jemal A, Bray F, Center MM, Ferlay J, Ward E, Forman D. Global cancer statistics. CA Cancer J Clin 2011; 61: 69-90.
2 Inamura $\mathrm{K}$, Ishikawa $\mathrm{Y}$. Lung cancer progression and metastasis from the prognostic point of view. Clin Exp Metastasis 2010; 27: 389-97.

3 Mihaljevic AL, Michalski CW, Friess H, Kleeff J. Molecular mechanism of pancreatic cancer - understanding proliferation, invasion, and metastasis. Langenbecks Arch Surg 2010; 395: 295-308.

4 Hoon DS, Ferris R, Tanaka R, Chong KK, Alix-Panabieres C, Pantel K. Molecular mechanisms of metastasis. J Surg Oncol 2011; 103 : 508-17.

5 Andjelkovic T, Bankovic J, Stojsic J, Milinkovic V, Podolski-Renic A, Ruzdijic S, et al. Coalterations of p53 and PTEN tumor suppressor genes in non-small cell lung carcinoma patients. Transl Res 2011; 157: 19-28.

6 Yoneda M, Suzuki T, Nakamura T, Ajima R, Yoshida Y, Kakuta S, et al. Deficiency of antiproliferative family protein Ana correlates with development of lung adenocarcinoma. Cancer Sci 2009; 100: 22532.

7 Mukhopadhyay UK, Mooney P, Jia L, Eves R, Raptis L, Mak AS. Doubles game: Src-Stat3 versus p53-PTEN in cellular migration and invasion. Mol Cell Biol 2010; 30: 4980-95.

8 Cristofanilli M, Krishnamurthy S, Guerra L, Broglio K, Arun B, Booser $\mathrm{DJ}$, et al. A nonreplicating adenoviral vector that contains the wildtype p53 transgene combined with chemotherapy for primary breast cancer: safety, efficacy, and biologic activity of a novel gene-therapy approach. Cancer 2006; 107: 935-44.

9 Matsuda S, Kawamura-Tsuzuku J, Ohsugi M, Yoshida M, Emi M, Nakamura Y, et al. Tob, a novel protein that interacts with p185erbB2, is associated with anti-proliferative activity. Oncogene 1996; 12: 705-13.

10 Winkler GS. The mammalian anti-proliferative BTG/Tob protein family. J Cell Physiol 2010; 222: 66-72.

11 Wang XM, Gao X, Zhang XH, Tu YY, Jin ML, Zhao GP, et al. The negative cell cycle regulator, Tob (transducer of ErbB-2), is involved in motor skill learning. Biochem Biophys Res Commun 2006; 340: 1023-7.

12 Jia S, Meng A. Tob genes in development and homeostasis. Dev Dyn 2007; 236: 913-21.

13 Mauxion F, Chen CY, Seraphin B, Shyu AB. BTG/TOB factors impact deadenylases. Trends Biochem Sci 2009; 34: 640-7.

14 Yoshida Y, Nakamura T, Komoda M, Satoh H, Suzuki T, Tsuzuku JK, et al. Mice lacking a transcriptional corepressor Tob are predisposed to cancer. Genes Dev 2003; 17: 1201-6.

15 Iwanaga K, Sueoka N, Sato A, Sakuragi T, Sakao Y, Tominaga M, et al. Alteration of expression or phosphorylation status of tob, a novel tumor suppressor gene product, is an early event in lung cancer. Cancer Lett 2003; 202: 71-9.

16 Ito Y, Suzuki T, Yoshida H, Tomoda C, Uruno T, Takamura Y, et al. Phosphorylation and inactivation of Tob contributes to the progression of papillary carcinoma of the thyroid. Cancer Lett 2005; 220: $237-$ 42.

17 Yoshida Y, von Bubnoff A, Ikematsu N, Blitz IL, Tsuzuku JK, Yoshida $\mathrm{EH}$, et al. Tob proteins enhance inhibitory Smad-receptor interactions to repress BMP signaling. Mech Dev 2003; 120: 629-37.

18 Helms MW, Kemming D, Contag $\mathrm{CH}$, Pospisil H, Bartkowiak K, Wang A, et al. TOB1 is regulated by EGF-dependent HER2 and EGFR signaling, is highly phosphorylated, and indicates poor prognosis in nodenegative breast cancer. Cancer Res 2009; 69: 5049-56.

19 Yoshida Y, Tanaka S, Umemori H, Minowa O, Usui M, Ikematsu N, et al. Negative regulation of BMP/Smad signaling by Tob in osteoblasts. Cell 2000; 103: 1085-97.

20 Wu QF, Liu C, Tai MH, Liu D, Lei L, Wang RT, et al. Knockdown of FoxM1 by siRNA interference decreases cell proliferation, induces cell 
cycle arrest and inhibits cell invasion in $\mathrm{MHCC}-97 \mathrm{H}$ cells in vitro. Acta Pharmacol Sin 2010; 31: 361-6.

$21 \mathrm{Li} \mathrm{XL}$, Meng QH, Fan SJ. Adenovirus-mediated expression of UHRF1 reduces the radiosensitivity of cervical cancer HeLa cells to gammairradiation. Acta Pharmacol Sin 2009; 30: 458-66.

22 Jiao Y, Ge CM, Meng QH, Cao JP, Tong J, Fan SJ. Adenovirus-mediated expression of Tob1 sensitizes breast cancer cells to ionizing radiation. Acta Pharmacol Sin 2007; 28: 1628-36.

23 Jiao Y, Ge CM, Meng QH, Cao JP, Tong J, Fan SJ. Dihydroartemisinin is an inhibitor of ovarian cancer cell growth. Acta Pharmacol Sin 2007; 28: $1045-56$.

24 Wu CY, Wu MS, Chiang EP, Chen YJ, Chen CJ, Chi NH, et al. Plasma matrix metalloproteinase-9 level is better than serum matrix metalloproteinase-9 level to predict gastric cancer evolution. Clin Cancer Res 2007; 13: 2054-60.

25 Takata F, Dohgu S, Matsumoto J, Takahashi H, Machida T, Wakigawa T, et al. Brain pericytes among cells constituting the blood-brain barrier are highly sensitive to tumor necrosis factor-alpha, releasing matrix metalloproteinase-9 and migrating in vitro. J Neuroinflammation 2011; 8: 106.

26 O'Malley S, Su H, Zhang T, Ng C, Ge H, Tang CK. TOB suppresses breast cancer tumorigenesis. Int J Cancer 2009; 125: 1805-13.

27 Yanagie H, Tanabe T, Sumimoto H, Sugiyama H, Matsuda S, Nonaka Y, et al. Tumor growth suppression by adenovirus-mediated introduction of a cell-growth-suppressing gene tob in a pancreatic cancer model. Biomed Pharmacother 2009; 63: 275-86.

28 Park GT, Seo EY, Lee KM, Lee DY, Yang JM. Tob is a potential marker gene for the basal layer of the epidermis and is stably expressed in human primary keratinocytes. Br J Dermatol 2006; 154: 411-8.

29 Tzachanis D, Boussiotis VA. Tob, a member of the APRO family, regulates immunological quiescence and tumor suppression. Cell Cycle 2009; 8: 1019-25.

30 Lee EY, Muller WJ. Oncogenes and tumor suppressor genes. Cold Spring Harb Perspect Biol 2010; 2: a003236.

31 Hurst DR, Welch DR. Metastasis suppressor genes at the interface between the environment and tumor cell growth. Int Rev Cell Mol Biol 2011; 286: 107-80.

32 Lin ML, Lu YC, Chung JG, Wang SG, Lin HT, Kang SE, et al. Downregulation of MMP-2 through the p38 MAPK-NF-kappaB-dependent pathway by aloe-emodin leads to inhibition of nasopharyngeal carcinoma cell invasion. Mol Carcinog 2010; 49: 783-97.

33 Wang S, Cheng Z, Yang X, Deng K, Cao Y, Chen H, et al. Effect of wild type PTEN gene on proliferation and invasion of multiple myeloma. Int J Hematol 2010; 92: 83-94.

34 Abou Youssif T, Fahmy MA, Koumakpayi IH, Ayala F, Al Marzooqi S, Chen $\mathrm{G}$, et al. The mammalian target of rapamycin pathway is widely activated without PTEN deletion in renal cell carcinoma metastases. Cancer 2011; 117: 290-300.

35 De Roock W, De Vriendt V, Normanno N, Ciardiello F, Tejpar S. KRAS, BRAF, PIK3CA, and PTEN mutations: implications for targeted therapies in metastatic colorectal cancer. Lancet Oncol 2011; 12 : 594-603.

36 Ho-Pun-Cheung A, Assenat E, Bascoul-Mollevi C, Bibeau F, BoissièreMichot F, Cellier D, et al. EGFR and HER3 mRNA expression levels predict distant metastases in locally advanced rectal cancer. Int J Cancer 2011; 128: 2938-46.

37 Pennell NA, Lynch TJ Jr. Combined inhibition of the VEGFR and EGFR signaling pathways in the treatment of NSCLC. Oncologist 2009; 14 : 399-411.
38 Capodanno A, Camerini A, Orlandini C, Baldini E, Resta ML, Bevilacqua $\mathrm{G}$, et al. Dysregulated PI3K/Akt/PTEN pathway is a marker of a short disease-free survival in node-negative breast carcinoma. Hum Pathol 2009; 40: 1408-17.

39 Jin G, Kim MJ, Jeon HS, Choi JE, Kim DS, Lee EB, et al. PTEN mutations and relationship to EGFR, ERBB2, KRAS, and TP53 mutations in non-small cell lung cancers. Lung Cancer 2010; 69: 279-83.

40 Piguet AC, Dufour JF. PI(3)K/PTEN/AKT pathway. J Hepatol 2011; 54: 1317-9.

41 Weickhardt AJ, Tebbutt NC, Mariadason JM. Strategies for overcoming inherent and acquired resistance to EGFR inhibitors by targeting downstream effectors in the RAS/PI3K pathway. Curr Cancer Drug Targets 2010; 10: 824-33.

42 Blanco-Aparicio C, Renner O, Leal JF, Carnero A. PTEN, more than the AKT pathway. Carcinogenesis 2007; 28: 1379-86.

43 Kojima M, Morisaki T, Sasaki N, Nakano K, Mibu R, Tanaka M, et al. Increased nuclear factor-kB activation in human colorectal carcinoma and its correlation with tumor progression. Anticancer Res 2004; 24 : 675-81.

44 Fu C, Jiang A. Generation of tolerogenic dendritic cells via the E-cadherin/beta-catenin-signaling pathway. Immunol Res 2010; 46: 72-8.

45 Lyon C, Mill C, Tsaousi A, Williams H, George S. Regulation of VSMC behavior by the cadherin-catenin complex. Front Biosci 2011; 16 : 644-57.

46 Zeljko M, Pecina-Slaus N, Martic TN, Kusec V, Beros V, Tomas D. Molecular alterations of E-cadherin and beta-catenin in brain metastases. Front Biosci (Elite Ed) 2011; 3: 616-24.

47 Stein U, Arlt F, Smith J, Sack U, Herrmann P, Walther W, et al. Intervening in beta-catenin signaling by sulindac inhibits S100A4-dependent colon cancer metastasis. Neoplasia 2011; 13: 131-44.

48 Phillips BT, Kimble J. A new look at TCF and beta-catenin through the lens of a divergent $C$ elegans Wnt pathway. Dev Cell 2009; 17: 27-34.

49 Xiong B, Rui Y, Zhang M, Shi K, Jia S, Tian T, et al. Tob1 controls dorsal development of zebrafish embryos by antagonizing maternal beta-catenin transcriptional activity. Dev Cell 2006; 11: 225-38.

50 Soto-Guzman A, Navarro-Tito N, Castro-Sanchez L, Martinez-Orozco $\mathrm{R}$, Salazar EP. Oleic acid promotes MMP-9 secretion and invasion in breast cancer cells. Clin Exp Metastasis 2010; 27: 505-15.

51 Sato H, Takino T. Coordinate action of membrane-type matrix metalloproteinase-1 (MT1-MMP) and MMP-2 enhances pericellular proteolysis and invasion. Cancer Sci 2010; 101: 843-7.

52 Poincloux R, Lizarraga F, Chavrier P. Matrix invasion by tumour cells: a focus on MT1-MMP trafficking to invadopodia. J Cell Sci 2009; 122: 3015-24.

53 Liu W, Zhou Y, Reske SN, Shen C. PTEN mutation: many birds with one stone in tumorigenesis. Anticancer Res 2008; 28: 3613-9.

54 Jiang BH, Liu LZ. PI3K/PTEN signaling in angiogenesis and tumorigenesis. Adv Cancer Res 2009; 102: 19-65.

55 Gildea JJ, Herlevsen M, Harding MA, Gulding KM, Moskaluk CA, Frierson $\mathrm{HF}$, et al. PTEN can inhibit in vitro organotypic and in vivo orthotopic invasion of human bladder cancer cells even in the absence of its lipid phosphatase activity. Oncogene 2004; 23: 678897.

56 Poon JS, Eves R, Mak AS. Both lipid- and protein-phosphatase activities of PTEN contribute to the p53-PTEN anti-invasion pathway. Cell Cycle 2010; 9: 4450-4. 